Research Article

\title{
Proposition of a Model for Selection of the Hybrid Contract Implementation Strategy for a Pilot Project of Regular Road Maintenance in Montenegro
}

\author{
Snežana Rutešićc $\mathbb{D}^{1},{ }^{1}$ Jasmina Ćetković $\mathbb{D},^{2}$ Slobodan Lakić $\mathbb{D}^{2},{ }^{2}$ Angelina Živković $\left(\mathbb{D},^{3}\right.$ \\ and Miloš Knežević $\mathbb{D}^{1}$ \\ ${ }^{1}$ University of Montenegro, Faculty of Civil Engineering, Podgorica 81000, Montenegro \\ ${ }^{2}$ University of Montenegro, Faculty of Economics, Podgorica 81000, Montenegro \\ ${ }^{3}$ Ministry of Transport and Maritime Affairs, Podgorica 81000, Montenegro \\ Correspondence should be addressed to Snežana Rutešić; snezanar@ucg.ac.me
}

Received 3 September 2020; Revised 27 October 2020; Accepted 29 October 2020; Published 19 November 2020

Academic Editor: Ivan Marović

Copyright (c) 2020 Snežana Rutešić et al. This is an open access article distributed under the Creative Commons Attribution License, which permits unrestricted use, distribution, and reproduction in any medium, provided the original work is properly cited.

Performance-based maintenance contracts (PBMCs) are modern contracts that should allow road maintenance entities to contract maintenance activities more successfully and generate money value. In the case of Montenegro, a gradual approach of PBMC introduction is recommended through a hybrid contract for routine road maintenance. Hybrid contract implementation will enable a lower level of client risk in the early stages of PBM contract. Game theory is used for selection of an adequate model for hybrid contract structure in terms of size and nature of the BoQ elements. In addition to the estimated or charged quantities of works from previous contracts, the model also includes parameters that to some extent take into account the experience and expertise of contractors and clients, but also the availability of road data. In order for model to be applied, historical data from traditional road maintenance contracts, which were implemented in the previous period in Montenegro, are used.

\section{Introduction}

The length of the Montenegrin road network is $6.848 \mathrm{~km}$. It is made up of $884 \mathrm{~km}$ main roads, of $964 \mathrm{~km}$ regional roads, and of around $5000 \mathrm{~km}$ local roads. Out of $1.848 \mathrm{~km}$ main and regional roads which are classified as state roads by the current law, 92\% are asphalt roads. According to the report [1], quality of roads, which are on the SEETO road network in Montenegro (length around $670 \mathrm{~km}$ ), is very good $2.24 \%$, good $37.39 \%$, medium $51.55 \%$, and poor $8.81 \%$.

Traffic Authority is a state entity under which jurisdiction is, among other activities, the management, development, construction, reconstruction, maintenance, and protection of state roads. The main management difficulties arise from unfavourable topography and geological structure of the terrain, very uneven, seasonal use of road infrastructure during the year, budgetary limitations and accumulated maintenance problems, lack of road infrastructure database, lack of private initiative in road sector, and an insufficiently shaped model of road and road network maintenance.

State road maintenance encompasses regular and investment maintenance in accordance with the midterm programme and annual plans. Investment maintenance is conducted on basis of technical documentation and contains construction works within the existing road profile in order for the lower array of the road to be renewed or replaced, improvement of construction road elements, repair of road facilities, landslide remediation, etc. Regular maintenance contains review, determination, and assessment of the state of the road; cleaning, ordering, and fixing of the road, walls, and other elements of the road (slopes and drainage systems) in places; repair of road facilities; cleaning, repair, and renewal of signalization and equipment; ordering of green 
surfaces along the road; maintenance and remediation of electrotechnical and machine installations in tunnels; cleaning of snow and ice, and covering of the road in case of ice; and maintenance and remediation of electrotechnical and machine installations in tunnels.

In the transition period, in the 1990s, very little was invested into maintenance, including regular maintenance. The situation changed in the beginning of the twenty-first century when there was an investment of 2.5 million euro into regular maintenance in 2003. Today, the investment is around 10 million annually. Starting with 2005, in accordance with public procurement procedures, four-year contracts are concluded for regular maintenance with selected contractors. These are traditional contracts which entail contracting and payment by unit prices of contracted works: measurement/input/based maintenance.

The traditional system aims at executing planned quantity of activities and not the effect which planned activities within given scope could have on the final condition of the road. In the traditional system, duty of the client (road maintenance entity) is expert supervision of quality and quantity control of executed works (in house or through a consultant) and payment of approved works. Programs and plans of regular road maintenance, the adoption of which is within jurisdiction of the road maintenance entity, need to be based on available financial resources, realistic assessment of the state of the road, importance of the road, traffic load, etc. in order to have optimal activity plan as a result. Programs and plans need to ensure that necessary activities are conducted on the right location (part of the road network), at the right time and with the required quality. The task of the contractor is to execute planned activities in accordance with technical standards in order to be paid for the conducted works, and the quantity and quality of which are determined through measurement. Mistakes in preparation of programs and plans result in an increased scope of variations and claims during the contract and are not at all desirable for any of the participants. Moreover, inadequate programs and plans of maintenance could lead to insufficient maintenance and a lack of undertaking preventive measures which leads to poorer condition of the roads regardless of resources available for regular maintenance. Application of the traditional model is faced with difficulties in terms of control of quality, time, and expenses. Moreover, according to papers analysed, the traditional method is frequently connected with a high level of political influence and corruption [2].

The other method applied in the world is performancebased maintenance contracting (PBMC). PBMC is a "method under which the selected contractor has to plan, design, and implement maintenance activities in order to achieve short- and long-term road condition standards for a fixed price, subject to specified risk allocation" [3] (p. 118). This method belongs in the performance-based contracting (PBC) which is defined as a type of contract in which payment for the deliverable is explicitly linked to the contractor's successfully meeting or exceeding certain clearly defined performance indicators $[4,5]$.
PBMC entails multiannual, lump sum contract, where the emphasis is put on the payment for the final result, i.e., performance of the maintained road. Performance levels are minimum conditions of road, bridge, road side, and traffic assets that must be met by the contractor over the entire contract period and may cover other services such as winter services, the collection and management of asset inventory data, call-out and attendance to emergencies, and response to public requests, complaints, and feedback. To optimize total system cost, performance levels may differ from traffic levels on a road section [5]. In this type of contract, performance levels and indicators are defined for each road asset or service provided under the contract. Fixed payments are made if performance levels are met, or payments are reduced due to noncompliance.

These contracts should inspire the contractor to apply innovative methods and procedures connected to maintenance, among other things, and to augment internal works control, in order to increase income and, at the same time, decrease expenses during the lifecycle of the roads by improving the level of quality of service $[5,6]$. Payment is done through a lump sum set on an annual or a monthly level after checking that the contractor is meeting the performance standards properly as defined in the contract. In that sense, it is important that performance levels should be easily understood, clearly defined, objectively and easily measurable, affordable, and consistent with relevant laws and regulations, and have low collection cost [3].

A large number of authors have analysed various aspects and models of PBMC application. In some works, the advantages of the PBMC method in compassion to the traditional method are emphases $[2,4,5,7]$ in following areas: cost savings, up to $40 \%$, or setting costs at a fixed level; better risk allocation; assurance of quality; more consistent (and/or better) service level and road users satisfaction; availability of initial funding sources; achieving a sustainable road management system; increased flexibility; increased transparency; and reducing the resource consumption for road authority. Some of indirect benefits for road maintenance entity are savings on rehabilitation costs, since roads in good condition avoid rehabilitation, and safeguards against cost overrun from frequent claims and contract amendments to increase quantities of work.

However, challenging factors which significantly influence PMBC application should also be mentioned, especially when it comes to developing countries. These are lack of support from government; dependency on external funding; political influence and corruption; lack of experience in introducing PBMC; lack of proper planning; fear of losing job; loss of competition; loss of control of the network; the contractors' performance and attitude; inflexibility to change anything once the contract has been started; and challenges in estimating the cost of PBMC especially because of the not sufficient understanding relationship between the financial cost of maintaining KPIs (key performance indicators) at a particular level, and it is a very high-risk area if the modelling predictions are not right levels [3]. Besides that, it is difficult to formulate a specific maintenance 
standard to define the maintenance operations, for roads in poor condition [5].

Outside of these two opposing methods of contracting, there is the hybrid contracting which is present in practice and which is treated in various manners in the literature [4], In this work, under a hybrid contract, we will consider a contract within which a part is contracted through the traditional method of unit prices and quantity measurements, and a part of contracted in accordance with PMBC principles. Payment for most of the services is being linked to meeting performance indicators. Application of this model should enable the combination of the best characteristics of both models in order for contract implementation to be optimal for each participant. This method can be used by the client (road maintenance entity) to adjust the sharing of risk between the contractor and client, mostly in cases when neither the client nor the contractor has enough knowledge to implement PBMC. Application of a hybrid contract carries a higher level of risk for the contractor in comparison to the traditional system but a lower level of risk in comparison to the PBMC. In opposition to this, the risk for the client is the highest in the traditional system and the lowest in the PBMC, being of a medium level in the hybrid model.

The first steps to initiating PBMC systems should be confined to a relatively simple contract (s) for PBM covering the routine maintenance of a package of roads, mostly in a hybrid manner, to only a carefully selected part of the network. The first step to initiating PBMC systems is conduction of the pilot project, in which the purpose is to test the existing institutional framework for longer-term implementation of PBMC; induce changes in the road maintenance system; test market readiness; establish the right balance of risk allocation between participants; create critical mass of knowledge; and expertise in the road maintenance entity and the local contracting industry to implement new types of maintenance contracts [7].

Preparation and implementation of a pilot project requires preliminary considerations about the following: (1) legal, regulatory, and financial climate, (2) data, (3) longterm strategy, (4) selection of roads for pilot projects, (5) technical assistance (and fields of assistance), (6) pilot implementation, (7) the contract, (8) allocation of risk, and (9) the timeline for a pilot PBM contract [5].

After analysing the state of road maintenance in Western Balkan countries, the key recommendations are given to improve the situation in this area: establishing proper practice of road network data collection, and structure budget into categories (routine and winter maintenance, periodic maintenance, rehabilitation, structures' maintenance, and emergency works); establishing database and GIS systems; establishing regular maintenance analysis and studies on short- and medium-term basis, and regular budget allocations for update of data and general work on the asset inventory; making a strategic decision on how to collect data; establishing the basics of the system and implement asset management principles; and performing asset valuation at regular intervals (not to exceed 2 to 3 years) [1].
The implementation of some of the above recommendations in the road maintenance policy in Montenegro is ongoing.

\section{Materials and Methods}

Introduction of the PBMC methodology implies launching a small-scale pilot project that would allow both the road maintenance entity and the contractors to adopt a different approach. Successful implementation of the pilot project requires an adequate strategy that would enable road maintenance entities to contract maintenance activities more successfully and get value for money.

Assessment of impact of different factors on the PBCM project success, as well as the possibility of optimization and appropriate model selection, were the subject of interest of researchers, although only a few of them investigated the simultaneous effect of several factors [8-10].

Gericke et al. [4] assume that the procurement of PBC would deliver $20 \%$ greater VfM than a non-PBC contract. According to the results achieved on two pilot maintenance projects in Serbia (total length of $1,200 \mathrm{~km}$, which were realized as hybrid contracts in the period from 2004 to 2007), the pilot project territories achieved routine maintenance cost savings in range from $31 \%$ to $55 \%$, average $46 \%$ for 5 years compared with the central region of Serbia during the same period [11]. The main challenge in those projects was the lack of sufficient qualified staff with the road administration, consultants, and contractors [5].

Some of the analysed factors in the literature from the aspect of the PBMC impact and success are as follows:

Contract duration, activity type, and contract size-the large projects with strong competition, long duration and extension periods, long outsourced road sections that incorporate crack sealing, pothole repair, illumination repair/maintenance, and mowing activities, and favour PBMC [8]

Cumulative equivalent single axle load, speed of construction work, the traffic, and rainfall have been used in the game theory and the simulation for the optimization of benefit for the client and profit for the contractor [9]

Performance levels and contractual performance criteria [4], [12] and thresholds for applying penalties/ incentives [13]-mathematical optimization models and a computational tool have been developed in order to meet contractual conditions: (1) types of performance indicators; (2) their threshold levels; and (3) the appropriate levels of penalties and incentives [10]

Risks allocation between the participants $[2,4,14,15]$ : if too much risk is allocated to the contractor, the price will be high, and if too little risk is transferred, then the goal of obtaining efficiency and effectiveness of the contract is not achieved [9] 
The method of contractor selection-cost reductions was largest when contractors faced strong competition and have gained experiences with PBCs [5]

Based on the analysed literature, the factors influencing the pilot project implementation can be divided as follows:

(1) Factors that are variable during the project implementation and which cannot be controlled by the project participants (uncontrolled factors): political, legal and regulatory, monetary, macroeconomic, climate, force majeure, traffic volume, axle loads, etc.

(2) Factors that are a consequence of the initial state of the system in which the project is implemented: availability of necessary knowledge and training, competence and competition of contractors, scope and timeliness of available road data, assess of existing road, availability of resources for contract execution, etc.

(3) Factors that are initially determined by the client (road maintenance entity) with the purpose of achieving the greatest value of money through the project implementation, and on the basis of which, the tender documentation and selection of contractors are prepared. The most important factors are as follows: duration of contract, location, and road included, type of maintenance activity that will be included, size contract, risk allocation, performances levels, type of PBMC (pure or hybrid, and size and nature of the BoQ elements), penalties systems, efficient performance monitoring and inspection system, etc.

Although the interaction of these factors is significant, the third group of factors deserves special attention, because they enable the selection of the optimal strategy of the road maintenance entity.

There are general recommendations for each of these factors $[1,5,7,16]$ and specifically for Montenegro [17]:

Duration of contract: pilot contract duration of 5 years is recommended for Montenegro.

Road included and location: the actual choice should be made based on the study. Neighbouring roads should be selected, in a limited area, in order to facilitate the execution of works, but also the performance of supervision. The recommended road length for Montenegro pilot project would be of $180-300 \mathrm{~km}$. It would be desirable to have a maintenance center location in the selected area.

Performances levels: it is necessary to set out appropriate level of service for different road types and traffic levels. Accordingly, the appropriate optimal number of maintenance performance indicators should be determined. These indicators should be clearly defined in the specifications (maintenance standards), easy to calculate and evaluate, realistic and achievable.

Type of maintenance activity that will be included is as follows: the contract should cover all routine maintenance (including winter maintenance). Regular road maintenance in Montenegro, according to the Law on Roads, includes routine maintenance and elements of periodic maintenance for which it is not necessary to do technical documentation (periodic maintenance is not specifically defined by law). The law also defines investment maintenance for which it is necessary to prepare technical documentation. The condition of the road depends on routine maintenance, but periodic maintenance (in the form of paving, surface treatment, or other bituminous treatments) has the greatest impact on preventing road deterioration, as it is necessary to include both components in terms of sustainability of the required performance level. A step-by-step approach is envisaged.

Size contract: it is recommended to allocate between 4,000 and $6,000 € / \mathrm{km} /$ year for routine and winter maintenance for pilot project in Montenegro.

Type of PBMC (pure or hybrid): the implementation of hybrid contracts will enable a lower level of client risk in the early stages of PBM contract implementation. This is particularly desirable for application in case of insufficient client experience.

Risk allocation: in pilot projects, it is desirable for the client to fully take risk of emergency works, some other physical works, and legal and regulatory changes. On the other hand, the contractor should take the risk related to the physical works (cost amount and timing). Other risks should be shared between the client and the contractor, so that the client assumes most of the risks related to price escalation and site access and $3^{\text {rd }}$ party activity, a contractor, a smaller part of these risks. Also, the contractor is expected to assume most of the risk related to asset management and traffic and axle load variation.

Penalties systems: penalties must be adequately defined. They are applied in cases when the contractor does not perform the maintenance standards, i.e., when maintenance functions are not performed properly on time. Reduction variants also depend on whether the job positions are paid in a lump sum or according to the BoQ system. In the case of positions that are paid as a lump sum, it is possible to reduce the fixed amount, or the percentage of the lump sum, or to award penalty points (demerit points) for each omission with the agreed value of penalty points. In the latter case, the total value of all penalties is also agreed. In the case of positions paid on the basis of BoQ, the reduction is made in the event that the execution is delayed or due to failure to achieve the defined quality of these positions. In pilot projects, it is recommended that in the contracts, first, until the contractor gains experience, a certain number of errors are allowed for which the payment is not reduced. In the following years, the number of allowed errors decreases.

Efficient performance monitoring and the inspection system: performance monitoring is a key to the success 
and manner and monitoring inspections' frequency. Monitoring methodology should be clearly defined and spelled out in the contract. It implies that experts who are specially trained in the PBMC application participate in this.

As noted, in the case of Montenegro, a gradual approach to the introduction of PBMC is recommended through a hybrid contract for routine road maintenance. The combination of BoQ and lump sum elements of works in hybrid contracts depends not only on the degree of risk that the client wants to transfer to the contractor, but also on the financial resources available formaintenance.

The risks associated with fixed-price contracts (such as "pure" PBMC) are the costs associated with project change. If a change occurs on the project that requires a change order from the contractor, the price of the change is typically very high. Even when the price for changes is included in the original contract, changes on a fixed-price contract will create higher total project costs than other forms of contracts because the majority of the cost risk is transferred to the contractor, and most contractors will add a contingency to the contract to cover their additional risk. In the other hand, the hybrid contract provides a calibrating risk allocation between the client and contractor, simply by adjusting the size and nature of the BoQ elements. In essence, the shorter the contract, the more risks it is appropriate for the client (road maintenance entity) to carry. In this regard, the issue of the size and nature of the BoQ elements in the hybrid contract is elevated.

Some of the recommendations for the contract structure are the follows:

Emergency maintenance, periodical maintenance works, minimal rehabilitation (if unavoidable), and some works of winter maintenance should be paid as BoQ elements $[1,16]$

The payment for the more variable or contentious elements should be made on the basis of measured quantities and unit rates, BoQ [7]

Based on experiences in the region, only cyclical regular maintenance activities, which require a small amount of material, or material is not needed at all, should be included in the lump sum and paid based on satisfied performance levels, i.e., treated as performance-based items, and other works to be calculated and paid for as BoQ elements [16]

In the continuation, a model for choosing the structure of a hybrid contract in terms of size and nature of the BoQ elements will be proposed. In that sense, we will consider the possibility of game theory application.

Game theory is a complex scientific field that deals with strategic decision-making in different situations, in which several decision makers participate with different interests [18]. The essence of all game theory definitions is the existence of conflict (of different levels) between participants (players) who make decisions, with defined rules, in order to choose from all available strategies those that allow the best game outcomes. The process of rational decision-making in different conflict levels and players' interests, as well as in risk and uncertainty conditions, can be mathematically formalized and analysed by game theory application. Each game consists of three important components: (1) there are at least two individuals called players. (2) Each player has a set of actions which he/she may follow. These courses of actions are named strategies. (3) The outcome of each strategy is determined and associated with each outcome, and there is a value named payoff for each player [19].

Despite some limitations, game theory has found application in a variety of business areas. It is especially applicable in various areas of project management [20], selection of bidders in construction or in general [21-23]. In addition, some papers discuss the application of this theory from the aspect of defining an appropriate contract model $[24,25]$. The interest of some authors was focused on publicprivate procurement $[26,27]$, on resolving disputes or cooperation in the PBMC project implementation $[9,28]$.

Special groups of games are games against nature. There is only one player who makes a rational choice and is interested in the outcome. The player (called "decision maker") only needs to list available options and then choose the optimal outcome. There does not exist a conscious opponent because nature is presumed to be completely indifferent to the player's decision. However, these games can also be treated and solved as two-person games. The basic assumption is that nothing is known about the probability distribution governing nature's "selection" of states [19]. Both players (player and nature) are assumed to have finitely many pure strategies and the $m$ by $n$ "payoff" matrix $A=\left[a_{i j}\right]$ is known. The $a_{i j}$ is assumed to represent the gain obtained by decision maker if he applies his $i$-th strategy while nature is in state $j$.

\section{Proposition of Model for Choosing the Structure of a Hybrid Contract in terms of Size and Nature of the BoQ}

Defining the structure of a hybrid contract from the point of size and nature of the BoQ elements may be seen as a game against the nature. The player is an investor (road maintenance entity), while the nature represents the conditions that can have a crucial influence on the client's decisions. We start from the assumption that the client may have different benefits if they use a specific position of work (work item) from the contract (contracts per unit rate) in relation to the strategy that the same work item defined at the flat rate price (lump sum). The amount of its benefits in both cases depends on the conditions in which the client makes the decision and which also influence prices that are expected from the bidder. The whole situation should be seen in the context of uncertainty, i.e., limited knowledge of the conditions in which the client should make a decision.

The client has two strategies at disposal regarding each work item from the PBMC pilot project. Work item may be agreed in such a way that it is calculated and paid as follows: 
Lump sum item: the payment is made based on the price from the contract, without the influence of the change of quantities to the contracted price, or

Unit rate item: the payment is made on the basis of measured quantities and unit rates, BoQ

In the first case the responsibility of the client lies only in establishing whether the works have been completed in accordance with the specifications and standards; they do not measure the quantities of the completed works for the needs of payment for the work. Defining the quantities that will be realized (and therefore paid) is the responsibility of the contractor.

In the second case, defining the quantities that will be realized (and therefore paid) is the responsibility of the client, because they order and approve their realization. The payment is made based on the measured quantity of work and the contracted unit rate. Of course, it is mandatory to achieve the performances defined by the contract as well as specification for that specific work item. It is assumed that in both cases, the risk allocation model of other uncontrolled factors is defined (political, legal and regulatory, monetary, macroeconomic, climate, force majeure, traffic volume, axle loads, etc.). These factors may have an impact on both prices and quantities.

The savings that the client may have if they make a contract in one or the other way will be the client's payoff. In order to calculate it, the prices for specific work item should be assumed. These prices are obtained in the tender procedure by selection of the contractor and the representation of the factor of uncertainty in this problem.

Depending on this, the contractor may use different approaches to defining their prices for the needs of the bid and contract. In both cases, the price depends on the price of necessary resources for the item realization, but also on the risks that may influence the change of prices of resources and they are a consequence of uncontrolled factors. In case of contracting the works as lump sum, the contractor will also calculate the risk that refers to the change of the quantity of works due to the impact of uncontrolled factors.

The contracted prices, paid by the client for a specific work item, for the two previous cases, may be presented:

$$
\begin{aligned}
C_{\mathrm{BoQ}} & =q_{m} \cdot\left(c_{r}+r_{r}\right), \\
C_{\mathrm{LS}} & =q_{c} \cdot\left(c_{r}+r_{r}+r_{q}\right),
\end{aligned}
$$

where $C_{\mathrm{BoQ}}$ is the total price when it is contracted as BoQ, $C_{\mathrm{LS}}$ is the total price when it is contracted as LS, $q_{m}$ is the measured quantity of works to be paid, $q_{c}$ is the estimated quantity of works that the contractor calculated when preparing his bid, and it is unknown to the client, $c_{r}$ is the price of resources expressed by the work item measurement units, based on the estimate of the contractor when preparing his bid, $r_{r}$ is a part of the unit rate of the contractor which includes the risks that may influence the change of the price of resources, and $r_{q}$ is a part of the unit rate of the contractor which included the risk that refers to wrongly estimated $q_{c}$, based on the estimate of the contractor when drafting the bid. It is assumed that this amount will always be $\geq 0$.
The contractor shall always include the cost of risk in their tender price, so it is assumed that $r_{r} \geq 0$ and $r_{q} \geq 0$. They present the planned price reserve that the contractor defined at the moment of submitting the bid (price premium due to the fear of the unknown). If work items are not described in reasonable detail by the available data, the contractor will have to increase its offered prices [7].

In the context of the PBMC contract, it is also necessary to consider and incorporate into the problem and work item quantity that is necessary to do in order to achieve the required maintenance standards and keep the performance level. From the point of view of the client, multiplying this quantity and the contractor's prices could lead to the calculation of the necessary costs of items in both cases, as shown in the following equations:

$$
\begin{aligned}
\mathrm{NC}_{\mathrm{BoQ}} & =q_{n} \cdot\left(c_{r}+r_{r}\right), \\
\mathrm{NC}_{\mathrm{LS}} & =q_{n} \cdot\left(c_{r}+r_{r}+r_{q}\right),
\end{aligned}
$$

where $\mathrm{NC}_{\mathrm{BoQ}}$ is the necessary costs for a specific work item, when it is contracted as $\mathrm{BoQ}, \mathrm{NC}_{\mathrm{LS}}$ is the necessary costs for a specific work item when it is contracted as LS, and $q_{n}$ is the quantity of works necessary to do in order to achieve the required maintenance standards.

There are opportunities for the contractor to increase profit margins when the work item is contracted according to LS. Rationalisations, improved efficiencies, and effectiveness of design, process, technology, or management can reduce the cost of achieving the specified service levels [5]. In that sense, the contractor will strive to achieve $q_{n}$.

The total benefit (cost savings) that the client may get is shown by

$$
\begin{gathered}
\mathrm{CS}_{\mathrm{Boq}}=\left(C_{\mathrm{LS}}-C_{\mathrm{BoQ}}\right)-\left(C_{\mathrm{BoQ}}-\mathrm{NC}_{\mathrm{BoQ}}\right), \\
\mathrm{CS}_{\mathrm{LS}}=\left(C_{\mathrm{Boq}}-C_{\mathrm{LS}}\right)-\left(C_{\mathrm{LS}}-\mathrm{NC}_{\mathrm{LS}}\right),
\end{gathered}
$$

where $\mathrm{CS}_{\mathrm{BoQ}}$ is the total savings for a specific work item, when it is contracted as BoQ, and $\mathrm{CS}_{\mathrm{LS}}$ is the total savings for a specific work item when it is contracted as LS.

The first part of these equations expresses savings arising directly from the manner of contracting the price. That part is reduced by the costs that could be avoided if the quantity of the works done was equal to those that are necessary.

Let us assume the following, according to

$$
\begin{aligned}
& u=q_{n}-q_{m}, \\
& v=q_{n}-q_{c} .
\end{aligned}
$$

where $u$ is the difference of the quantity of work necessary to do and the quantity ordered/approved by the client in case of contracting BoQ. This value also depends on the responsibility and qualifications of the client, but also on the available date on the situation of the road. If $u<0$, the client approved less than the necessary quantities, which will eventually mean increase of costs in the future maintenance because of the road deterioration. The case $u>0$ means better maintenance level than the one contracted and 
reduction of costs in the future. The case $u=0$ means that the quantity of realized, approved, and paid works represents the proper measure for adequate maintenance based on the contract. $v$ is the difference of the quantity which is necessary to do and the quantity estimated by the contract when drafting the bid, in case of contracting LS. It should be repeated that in case of contracting the work item based on LS, the contractor is responsible for defining the quantity necessary to do in order to achieve the maintenance standard.

It has already been mentioned that in case of contracting the work item based on LS, the contractor estimates the quantity of work $q_{c}$. For the estimation of the total price $C_{\mathrm{LS}}$ for that specific work item, the contractor took into account the unit rate in which they included the reserve $r_{q} \geq 0$. A link may be established among this reserve $r_{q}$, the quantity of work $q_{c}$ estimated by the contractor, the quantity of work necessary to achieve the standard $q_{n}$, the estimated price of resources $c_{r}$, and the estimated reserve $r_{r}$ according to

$$
r_{q}=\frac{\left(q_{n}-q_{c}\right)}{q_{c}}\left(c_{r}+r_{r}\right)=\frac{v}{q_{c}}\left(c_{r}+r_{r}\right) .
$$

Due to the conditions $r_{q} \geq 0$ and equation (9), the following may be concluded by

$$
\begin{aligned}
& v>0 \Longrightarrow r_{q}=\frac{v}{q_{c}}\left(c_{r}+r_{r}\right), \\
& v=0 \Longrightarrow r_{q}=\frac{v}{q_{c}}\left(c_{r}+r_{r}\right), \\
& v<0 \Longrightarrow r_{q}=0 .
\end{aligned}
$$

Equation (10) refers to the case when the contractor underestimated the quantity of works to be done in order to meet the standards, and equation (12) refers to the case when the contractor, when drafting their bid, estimated the quantities to be realized. The case in which the contractor accurately estimated the quantities is expressed in equation (11). All the described situations may be a consequence of different experiences of contractors, but also of different levels of accuracy, as well as the availability of information on the existing state of the road.

Starting from equations (5) and (6), along with the application of the expressions provided in other equations, we get the expressions that can be used for calculation of the client's savings (payoff), depending on whether the contractor underestimated, overestimated, or accurately estimated the quantity of works when defining the $C_{\mathrm{SL}}$ price:

For the case $v \geq 0$, the client's savings (payoff) are

$$
\begin{aligned}
\mathrm{CS}_{\mathrm{BoQ}} & =2 u\left(c_{r}+r_{r}\right), \\
\mathrm{CS}_{\mathrm{LS}} & =\left[\left(\frac{v \cdot q_{m}}{q_{m}-v}-u\right)\right]\left(c_{r}+r_{r}\right),
\end{aligned}
$$

For the case $v<0$ the client's savings (payoff) are

$$
\begin{aligned}
\mathrm{CS}_{B o Q} & =(2 u-v)\left(c_{r}+r_{r}\right), \\
\mathrm{CS}_{L S} & =(2 v-u)\left(c_{r}+r_{r}\right) .
\end{aligned}
$$

where $\mathrm{CS}_{\mathrm{BoQ}}$ is the total savings for a specific work item, when it is contracted as BoQ, $\mathrm{CS}_{\mathrm{LS}}$ is the total savings for a specific work item, when it is contracted as LS, $c_{r}$ is the price of resources expressed by the work item measurement units, based on the estimate of the contractor when preparing his bid, $r_{r}$ is a part of the unit rate of the contractor which includes the risks that may influence a change of the price of resources, $q_{m}$ is the ordered/applied quantity of works that would be paid in case of contracting as BoQ, $u$ is the difference of the quantity of works necessary to do and the quantity that is ordered/approved by the client, in case of contracting as BoQ, and $v$ is the difference of the quantity of works necessary to do and the quantity estimated by the contractor when drafting the bid, in case of contracting as LS.

It is assumed that all the maintenance standards will be met, so the model does not take into account the penalties for not achieving the maintenance standards. In addition, the incentive system is not included.

We must bear in mind that $u$ and $v$ are the indicators whose distribution is unknown in advance, so they should also be included in possible states of nature.

The problem is reduced to the game against nature with two possible strategies of the client and the states of nature that depend on the indicators $u$ and $v$. In an extensive description, the game could be represented as in Figure 1(which was created using Gambit Software).

If we knew the probability of distribution governing the "selection" of the states of nature, the problem could be solved by the theory of statistical decisions [29].

We will simplify this model by introducing the assumption that $u=0$; that is, the client is responsible and well trained and has valid information on the state of roads based on which it is possible to accurately estimate the values $q_{n}$.

With this simplification, the matrix of the game is provided in Table 1. It shows the client's payoff for two possible strategies: (1) contract the given work item as unite price item (BoQ), and (2) contract the item as a lump sum item (LS). Another participant is "nature" which has 2 states whose distribution of probabilities is not known in advance.

If the client's payoff is divided by $\left(c_{r}+r_{r}\right)$, i.e., if the expected savings of the client are expressed in relation to $\left(c_{r}+r_{r}\right)$, that will not influence the choice of optimal strategy. In this way, we can express the client's savings as a relative saving in relation to the work item unit rate. The value of such an organized game should be multiplied with $\left(c_{r}+r_{r}\right)$ in order to get the value of initial game (Table 2). An equivalent game would, in such a situation, depend on the indicators $v$ and $q_{m}$. 


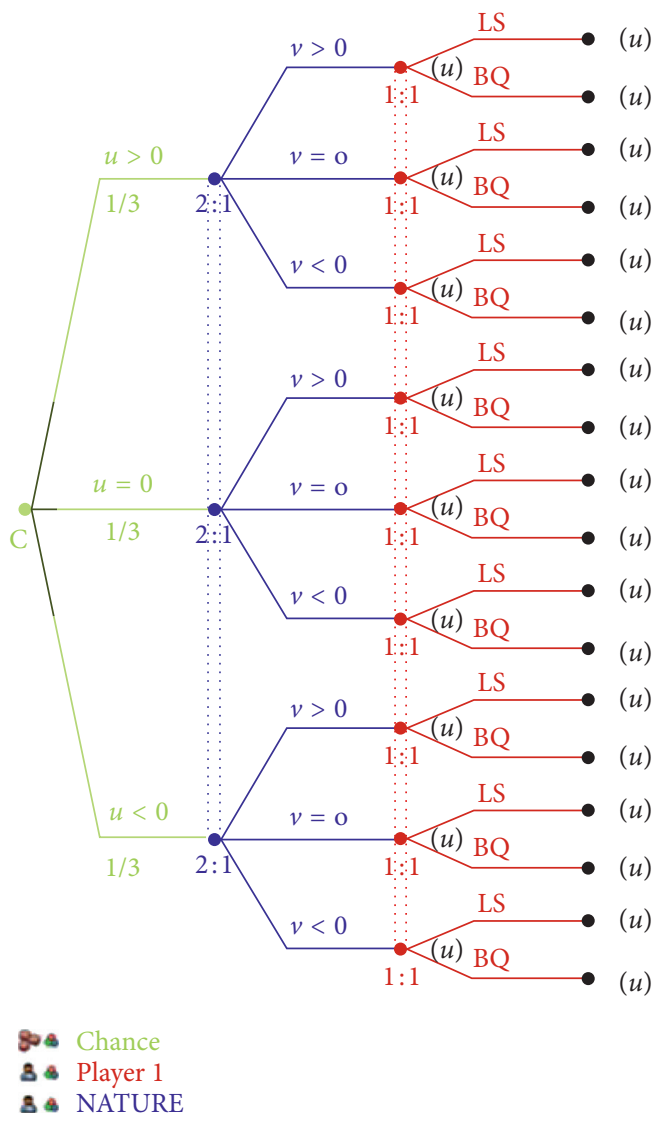

Figure 1: Extensive description of the game.

TABLe 1: The matrix of the simplified game.

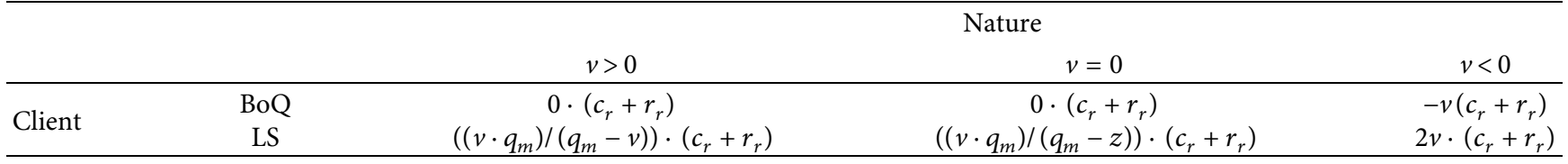

TABLE 2: The matrix of the equivalent game.

\begin{tabular}{ccccc}
\hline & & \multicolumn{2}{c}{ Nature } & \\
& & $v>0$ & $v=0$ & 0 \\
Client & BoQ & 0 & 0 & $-v$ \\
& LS & $\left(v \cdot q_{m}\right) /\left(q_{m}-v\right)$ & $\left(v \cdot q_{m}\right) /\left(q_{m}-v\right)$ & $2 v$ \\
\hline
\end{tabular}

\section{Results}

In this game against nature, the client makes decisions. According to the rules of game theory, they should behave rationally. The rationality of their choice depends on the criteria they apply, on his attitude towards risk, on their ideas about profit and loss, etc. [29]. On the other hand, nature is not considered a rational opponent. There are ways to choose optimal strategy for these types of games, and they include Laplace, Hurwitz, Wald, and Savage criteria [30]. "The mixed strategies in games against nature demand a high expertise and can only be found in situations where these strategies improve the effects of minimax-strategies that are used in cases of risk-aversion" [31] (p. 1).

4.1. Laplace Criterion. According to Laplace, all states of nature should be regarded as equally probable because nothing is known about the real probabilities [29]. According to this assumption, the choice of optimal strategy is reduced on the choice of the strategy that has the highest expected benefit for the participant. Practically, that means that payoff for each row of the matrix individually is added, and then the strategy that has the highest value of this sum is chosen. This criterion $c$ may be expressed by 


$$
c=f\left(a_{i j}\right)=\max \left(\frac{1}{m} \sum_{j}^{m} a_{i j}, i=1, \ldots, n\right) .
$$

4.2. Wald's (Maximin) Criterion. This criterion implies that the player (who is a pessimist) choses the most cautious position. The player supposes that the nature game is against him and that the most unfavourable situation for the player will occur. The player attempts to create the best outcome in this type of situation, which is known as the maximin principle. There are situations where using this criterion is justified: in cases when possible consequences of the decisions are unfavourable or when the possibility of predicting possible consequences is extremely low.

In this way, the player is choosing the saddle point strategy in a game if it contains a saddle point. In a game without a saddle point, that is a pure strategy, which is actually not the mixed strategy game solution [30]. This can be presented by

$$
c=f\left(a_{i j}\right)=\max \left[\min \left(a_{i j}\right), i=1, \ldots, n\right] .
$$

4.3. Hurwicz's Criterion. This approach is a kind of combination of the previous criterion. Hurwicz defines $\alpha$, as "the index of optimism" which is supposed to measure the attitude of the decision maker toward risk. The value $\alpha$ is between 0 and 1 , and the closer it is to 1 , the more the decision maker is considered a bigger optimist. When $\alpha=1$, the decision maker is the most optimistic; if $\alpha=0$, then he is the most pessimistic. This index is combined with Wald's criterion, which can be expressed by

$$
c=f\left(a_{i j}\right)=\max \left\{\alpha\left[\max \left(a_{i j}\right), i=1, \ldots, n\right]+(1-\alpha)\left[\min \left(a_{i j}\right), i=1, \ldots, n\right]\right\} .
$$

4.4. Savage's Criterion. This strategy is designed to minimize the maximum regret that a player may feel from a decision by creating a regret matrix $R=\left[r_{i j}\right]$. To create the regret matrix, a player will take each entry and subtract it from the highest entry in its column. If the entry is the highest entry in a column, then in the regret matrix, the corresponding value will be 0 , as shown in equation (20). This strategy is attempting to make the player feel as good as possible no matter the circumstances of their game play [30]. Then, in the matrix game $R$, the decision makers should apply Wald's (minmax) criterion. This can be presented by

$$
\begin{gathered}
r_{i j}= \begin{cases}a_{i j}-\max \left(a_{i j}\right), & a_{i j}-\max \left(a_{i j}\right)>0, j=1, \ldots, m, \\
0, & a_{i j}-\max \left(a_{i j}\right) \leq 0, j=1, \ldots, m,\end{cases} \\
c=f\left(a_{i j}\right)=c\left(r_{i j}\right)=\min \left[\max \left(r_{i j}\right), i=1, \ldots, n\right] .
\end{gathered}
$$

The optimal strategies of the client (decision makers) depend on the earlier-mentioned indicators $v$ and $q_{m}$, and of course, on the criterion he applies. In the context of the described problem and the adopted assumptions, we consider the application of the Laplace criterion justified.

There is possibility to apply the model before publishing the tender for the pilot project of maintenance according to PBCM. To that end, these indicators would be calculated based on the collected data on the implementation of the previous contracts on maintenance, which were enforced as input-based contracts with unit rates of works. For the needs of payments, the realized quantities of work $q_{m}$ were measured, and instead of the unknown value of the indicator $v$, we can anticipate the expected values of this indicator for each work item.

The contracted values of regular maintenance (with winter maintenance) in the previous period (from 2005 to the last contract from 2019) were between 8.5 million and 10 million euros per year. During the four-year contracts, there was a smaller deviation of realized value than the total agreed price $(1-5 \%)$.

For the implementation of the model, performance data of the contract from 2015 to 2019 were available. Performance data of previous contracts were not available, while the contract from 2019 was not taken into account as it is a four-year contract currently still in progress. The last completed four-year contract (2015-2019) identified 111 detailed out-of-winter maintenance elements (work elements) and 6 elements belonging to winter maintenance. The following data on the elements were available to us, by road sections (5 sections in total): $q_{m}$ is the quantity measured and approved for payment; $q_{e}$ is the quantity of work estimated in the tender; $c_{c}$ is the contracted unit prices.

Based on available data, we first selected the work elements for the model's application. We excluded winter maintenance works from consideration, because these works are variable and extremely dependent on climate conditions. In addition, for contracting these works as LS, special conditions must be met regarding the existence of climatological stations on the road network [28]. We selected other work elements according to the Pareto principle, by choosing from all elements those which, when added up, contribute to the final value of the contract (without the value of winter maintenance) around $85 \%$. In doing so, we merged some of the detailed work elements into one work item (given the same type of work, the same measurement units, and a similar unit price). In this way, we identified 14 work items we applied the model. Table 3 shows selected works items for model implementation, values of paid works per road sections (S1 to S5), and percentage of their contribution in total value of contracts (without winter maintenance).

For the assessment $v$, we used the next assumption: since the contract was a contract with unit prices, the contractor was not particularly interested in assessing the amount of 
TABLE 3: Overview of selected works for implementation of the model.

\begin{tabular}{|c|c|c|c|c|c|c|c|c|}
\hline \multirow[t]{2}{*}{ No. } & \multirow{2}{*}{ Description of the item } & \multirow{2}{*}{$\begin{array}{l}\text { Measurement } \\
\text { units }\end{array}$} & \multicolumn{5}{|c|}{$\begin{array}{l}\text { Value of paid works per road section for period } \\
\qquad 2015-2019(€)\end{array}$} & \multirow{2}{*}{$\begin{array}{c}\text { Contribution } \\
\text { in total value } \\
(\%)\end{array}$} \\
\hline & & & S1 & S2 & S3 & S4 & S5 & \\
\hline 1 & Hot patch asphalt (repair of larger surfaces) & $\mathrm{m}^{2}$ & $1,101,509$ & 892,105 & 858,927 & 729,203 & 591,949 & 22.17 \\
\hline 2 & $\begin{array}{c}\text { Protection of slopes with suspended steel wire } \\
\text { meshes }\end{array}$ & $\mathrm{m}^{2}$ & 696,213 & 483,358 & 633,173 & 314,801 & 601,186 & 14.49 \\
\hline 3 & Marking horizontal signalization lines & $\mathrm{km}$ & 536,609 & 495,607 & 312,100 & 314,797 & 401,497 & 10.94 \\
\hline 4 & Installation and replacement of safety fence & $\mathrm{m}$ & 199,129 & 271,258 & 303,084 & 182,555 & 229,004 & 6.29 \\
\hline 5 & $\begin{array}{l}\text { Hot patch asphalt (repair smaller surfaces and } \\
\text { potholes) }\end{array}$ & $\mathrm{t}$ & 12,828 & 235,571 & 322,500 & 206, 951 & 128,283 & 4.81 \\
\hline 6 & Inspection service & $\mathrm{h}$ & 215,461 & 183,298 & 122,467 & 140,096 & 238,960 & 4.78 \\
\hline 7 & Cleaning gutter & $\mathrm{m}$ & 151,941 & 128,779 & 110,145 & 207,225 & 188,878 & 4.18 \\
\hline 8 & Cleaning of landslide material & $\mathrm{m}^{3}$ & 134,357 & 146,023 & 19,813 & 228,236 & 242,095 & 4.09 \\
\hline 9 & Cutting shrubs, trees, and grass & $\mathrm{m}^{2}$ & 56,897 & 143,633 & 112,991 & 136,544 & 148,651 & 3.18 \\
\hline 10 & Laying of the levelling wearing course $\mathrm{AB} 11$ & $\mathrm{t}$ & 147,700 & 165,845 & 97,221 & 56,319 & 119,410 & 3.11 \\
\hline 11 & Forging slopes from unstable parts of rocks & $\mathrm{m}^{3}$ & 53,098 & 220,281 & 14,885 & 65,372 & 117,348 & 2.50 \\
\hline 12 & Repair of stone walls & $\mathrm{m}^{3}$ & 2,241 & 29,997 & 352,254 & 0 & 10,755 & 2.10 \\
\hline 13 & Cleaning of drainage channels and ditches & M & 22,037 & 79,487 & 91,205 & 98,386 & 42,086 & 1.77 \\
\hline \multirow[t]{2}{*}{14} & $\begin{array}{c}\text { Mechanical scraping-profiling of existing } \\
\text { asphalt pavement }\end{array}$ & $\mathrm{m}^{2}$ & 88,963 & 83,272 & 50,093 & 41,074 & 44,796 & 1.64 \\
\hline & & Total & & & & & & 86.06 \\
\hline
\end{tabular}

TABle 4: Game matrix.

\begin{tabular}{ccccc}
\hline & & & Nature & \\
& & $v>0$ & $v=0$ & $v<0$ \\
\hline \multirow{2}{*}{ Client } & BoQ & 0 & 0 & $-\left(q_{m}-q_{e}\right)$ \\
& LS & $\left(q_{m}-q_{e}\right) \cdot q_{m} / q_{e}$ & $\left(q_{m}-q_{e}\right) \cdot q_{m} / q_{e}$ & $2\left(q_{m}-q_{e}\right)$ \\
\hline
\end{tabular}

work that should be performed $\left(q_{c}\right)$ during the realization of the contract, because under that contract, the risk of quantity change was not under the responsibility of the contractor. We can, therefore, assume that it is $q_{c}=q_{e}$.

The second assumption is the same as the assumption of simplifying the model: we believe that the client has a lot of experience, responsibility, and knowledge, so he ordered, controlled, and approved payment, only the amount that needed to be performed. That means $q_{n}=q_{m}$, because $u=0$.

By respecting these two assumptions, based on equations (7) and (8), we get the difference of the quantity of works necessary to do and the quantity estimated by the contractor when drafting the bid, according to

$$
v=q_{n}-q_{c}=q_{m}-q_{e},
$$

where $q_{n}$ is the amount of work that is necessary to achieve the requirements, $q_{c}$ is the valued amount of work valued by the contractor in the formation of the offer, unknown to the client, $q_{m}$ is the measured amount of work to be paid for, $q_{e}$ is the amount of work valued by the client in the tender.

Based on this, we may write an expression for the payoff client, in which instead of $q_{m}$ and $q_{e}$, we will use the expected $q_{m}$ and $q_{e}$ values (Table 4 ).

Expected values $q_{m}$ and $q_{e}$ are reached on basis of values $q_{m}$ and $q_{e}$ per road sections and are shown in Table 5 .
The game matrix for item 1 and "hot patch asphalt (repair of larger surfaces)" are given in Table 6 .

If we assume equally probable state $(1 / 3)$, then, by applying Laplace criterion, the following solution is reached:

$$
\begin{aligned}
& \mathrm{OV}_{\text {Boq }}=\frac{1}{3}(0+0-31966)=-21310.5 \\
& \mathrm{OV}_{\mathrm{LS}}=\frac{1}{3}(70443+70443+63931)=68272.4 .
\end{aligned}
$$

Based on equations (23) and (24), we can conclude that for this item, the optimal strategy is contracting by the LS method.

Similarly, we can resolve games for other items of works using the Laplace criterion. Optimal values and game strategies are given in Table 7 . The same table (last column) provides recommendation regarding the manner of contracting of these items based on documents which refer to Serbia [16].

Discrepancies of the proposed strategies according to the model with recommendations from documents which refer to Serbia cannot be understood as incorrectness of the model. Opportunities and conditions in contract implementation regarding maintenance of roads are different from conditions in Montenegro; thus, in the case of the Serbian model, data from implementation of contracts should be applied in the model. 
TABLE 5: Expected values of $q_{m}$ and $v$ for selected works.

\begin{tabular}{|c|c|c|c|c|}
\hline No & Work item & Measurement units & Expected (qm) & Expected $v=q m-q e$ \\
\hline 1 & Hot patch asphalt (repair of larger surfaces) & $\mathrm{m}^{2}$ & 74,926 & 31,966 \\
\hline 2 & Protection of slopes with suspended steel wire meshes & $\mathrm{m}^{2}$ & 59,773 & 18,005 \\
\hline 3 & Marking horizontal signalization lines & $\mathrm{km}$ & 1,404 & -335 \\
\hline 4 & Installation and replacement of safety fence & $\mathrm{m}$ & 4,132 & $-5,068$ \\
\hline 5 & Hot patch asphalt (repair smaller surfaces and potholes) & $\mathrm{t}$ & 1,051 & -429 \\
\hline 6 & Inspection service & $\mathrm{h}$ & 9,484 & -48 \\
\hline 7 & Cleaning gutter & $\mathrm{m}$ & 720,151 & 2,991 \\
\hline 8 & Cleaning of landslide material & $\mathrm{m}^{3}$ & 12,771 & -257 \\
\hline 9 & Cutting shrubs, trees, and grass & $\mathrm{m}^{2}$ & $1,649,486$ & 62,286 \\
\hline 10 & Laying of the levelling wearing course $\mathrm{AB} 11$ & $\mathrm{t}$ & 1,178 & 523 \\
\hline 11 & Forging slopes from unstable parts of rocks & $\mathrm{m}^{3}$ & 5,497 & 2,812 \\
\hline 12 & Repair of stone walls & $\mathrm{m}^{3}$ & 2,128 & 1,124 \\
\hline 13 & Cleaning of drainage channels and ditches & $\mathrm{m}$ & 49,447 & 12,255 \\
\hline 14 & Mechanical scraping-profiling of existing asphalt pavement & $\mathrm{m}^{2}$ & 58,259 & 10,939 \\
\hline
\end{tabular}

TABle 6: Game matrix.

\begin{tabular}{lcccc}
\hline Pos. 1. & & Nature & \\
& & $v>0$ & $v=0$ & $v<0$ \\
\hline \multirow{2}{*}{ Client } & BoQ & 0 & 0 & $-31,966$ \\
& LS & 70,443 & 70,443 & 63,931 \\
\hline
\end{tabular}

TABLE 7: Overview of optimal strategies using the Laplace criterion $(p i=1 / 3)$ for selected works.

\begin{tabular}{|c|c|c|c|c|c|}
\hline No. & Work item & $\begin{array}{c}\text { Unit } \\
\text { measure }\end{array}$ & Laplace criterion for $p j=1 / 3$ & $\begin{array}{l}\text { Optimal } \\
\text { strategy }\end{array}$ & $\begin{array}{l}\text { Recommendation for } \\
\text { Serbian conditions }\end{array}$ \\
\hline 1 & Hot patch asphalt (repair of larger surfaces) & $\mathrm{m} 2$ & 68272.4 & LS & BoQ \\
\hline 2 & Protection of slopes with suspended steel wire meshes & $\mathrm{m} 2$ & 33105.0 & LS & BoQ \\
\hline 3 & Marking horizontal signalization lines & $\mathrm{km}$ & 111.6 & BoQ & BoQ \\
\hline 4 & Installation and replacement of safety fence & $\mathrm{m} 1$ & 1689.3 & BoQ & BoQ \\
\hline 5 & Hot patch asphalt (repair smaller surfaces and potholes) & $\mathrm{t}$ & 142.8 & BoQ & BoQ \\
\hline 6 & Inspection service & $\mathrm{h}$ & 16.1 & BoQ & LS \\
\hline 7 & Cleaning gutter & $\mathrm{m} 1$ & 4068.4 & LS & LS \\
\hline 8 & Cleaning of landslide material & $\mathrm{m} 3$ & 85.8 & BoQ & BoQ \\
\hline 9 & Cutting shrubs, trees, and grass & $\mathrm{m} 2$ & 82635.8 & LS & LS \\
\hline 10 & Laying of the levelling wearing course $\mathrm{AB} 11$ & $\mathrm{t}$ & 919.1 & LS & BoQ \\
\hline 11 & Forging slopes from unstable parts of rocks & $\mathrm{m} 3$ & 5636.0 & LS & LS \\
\hline 12 & Repair of stone walls & $\mathrm{m} 3$ & 3939.4 & LS & BoQ \\
\hline 13 & Cleaning of drainage channels and ditches & $\mathrm{m} 1$ & 107183.2 & LS & LS \\
\hline 14 & $\begin{array}{l}\text { Mechanical scraping-profiling of existing asphalt } \\
\text { pavement }\end{array}$ & $\mathrm{m} 2$ & 19028.7 & LS & BoQ \\
\hline
\end{tabular}

\section{Conclusion and Recommendations}

The proposed model can serve for the selection of work items which would be contracted based on the BoQ system in hybrid contract for the PBMC pilot project. In this manner, for the implementation of the PBMC pilot project, optimal saving for the client could be made, depending on the manner of contraction of specific work items. For the selection of items, historical data from previous contracts which are contracted by unit prices should be used.

In further research, additional expenses which the client would have in case of contracting certain work items in accordance with BoQ, i.e., the LS system, could be considered. These expenses would have an impact on the decrease of expected savings of the client, and in this manner, it would have an impact on optimal strategy.

\section{Data Availability}

The data used to support the findings of this study are available from the corresponding author upon request.

\section{Conflicts of Interest}

The authors declare that there are no conflicts of interest regarding the publication of this paper. 


\section{References}

[1] C. Consortium, Preparation of Maintenance Plans 2018-2022 for Road/Rail TEN-T Indicative Extensions to WB6, CONNECTA Consortium, New York, NY, USA, 2018.

[2] M. Sultana, A. Rahman, and S. Chowdhury, "A review of performance based maintenance of road infrastructure by contracting," International Journal of Productivity and Performance Management, vol. 62, no. 3, pp. 276-292, 2013.

[3] M. Sultana, A. Rahman, and S. Chowdhury, "Performance based maintenance of road infrastructure by contracting-A challenge for developing countries," Journal of Service Science and Management, vol. 5, no. 2, pp. 118-123, 2012.

[4] B. Gericke, T. Henning, and I. Greewood, Phase 1. Transport Papers Series No. TP-42A, World Bank, Washington, DC, USA, 2014.

[5] G. Zietlow, Guide to Performance-Based Road Maintenance Contracts, CAREC Secretariat at the Asian Development Bank, Azerbaijan, China, 2018.

[6] I. Jokanović, "Monitoring the implementation of performance based maintenance contracts," Building Materials And Structures, vol. 54, no. 4, pp. 7-24, 2011.

[7] R. International, Policy Challenges in the Implementation of Performance-Based Contracting for Road Maintenance, European Bank for Reconstruction and Development, London, UK, 2016.

[8] P. C. Anastasopoulos, B. G. McCullouch, K. Gkritza, F. L. Mannering, and K. C. Sinha, "Cost savings analysis of performance-based contracts for highway maintenance operations," Journal of Infrastructure Systems, vol. 16, no. 4, pp. 251-263, 2010.

[9] H. Tjendani, N. Anwar, and A. Wiguna, "Two stage simulation to optimize risk sharing in performance-based contract on national road-a system dynamic and game theory approach," ARPN Journal of Engineering and Applied Sciences, vol. 13 , no. 15 , p. $4432,2018$.

[10] A. S. Soliman, O. Hesham, and H. Ossama, "Optimal maintenance and rehabilitation policies for performancebased road maintenance contracts," Journal of Performance of Constructed Facilities, vol. 31, no. 1, 2017.

[11] N. Radović, K. Mirković, M. Šešlija, and I. Peško, “Output and perfomance based road maintenance contracting-case study Serbia," Tehnički vjesnik, vol. 21, no. 3, pp. 681-688, 2017.

[12] T. Yoshida, "Performance-based specification as a step to performance-based management and maintenance of pavement in Japan," in Proceedings of the IRF and ARF Asia Pacific Roads Conference and Exhibition, Sydney, Australia, September 2002.

[13] J. C. Piñero and J. M. de la Garza, "Issues related to the assessment of performance-based road maintenance contracts," 2004.

[14] B. Mochtar, H. Parung, J. Patanduk, and N. Ali, "Risk analysis for performance based contracting on the road construction work," ARPN Journal of Engineering and Applied Sciences, vol. 10, no. 12, pp. 5110-5118, 2015.

[15] C. Gelderman, J. Semeijn, and S. Vries, "Contracting for road maintenance in The Netherlands-the downside of performance-based contracting," Infrastructures, vol. 4, no. 3, p. 41, 2019.

[16] G. Williams, A. Spernol, V. Todorović, and J. Milanović, Uvođenje I Razvoj Održavanja Puteva Zasnovanog Na Definisanom Nivou Usluge Na Mreži Državnih Puteva Srbije, Aktivnost 2-Tehnički Izvještaj, PBMC Strateški plan EGIS International, Beograd, Serbia, 2015.
[17] Spea Engineering S.p.A, SIMM inzenjering, "PBMC strategy and model \& road safety regulation," 2015.

[18] A. Kapor, “Teorija igara: sistemski pristup i razvoj," 2017.

[19] R. Samsami, "Application of game theory in studying subcontractors' cooperation in construction projects-joint resource management," 2018.

[20] M. Piraveenan, "Applications of game theory in project management: a structured review and analysis," Mathematics, vol. 7, no. 9, p. 858, 2019.

[21] H. Chen, "Competitive bidding strategy in the construction industry-game theoretic approach," 1989.

[22] A. I. Kucsma, "Bidding for contract games applaying game theory to analyze first price sealed bid auctions," 1997.

[23] M. W. Kembłowski, B. Grzyl, and A. Siemasszko, "Game theory analysis of bidding for a construction contract," IOP Conference Series: Materials Science and Engineering, vol. 245, no. 6, Article ID 062047, 2017.

[24] A. Bedak-Tahirović and D. Zečić, "Primjer upotrebe teorije igara u teoriji ugovora," BH Ekonomski Forum, vol. 1, no. 1, pp. 63-82, 2010.

[25] C. Ipema, "Designing the perfect tender," 2014.

[26] D. De Clerck, "Public-private partnership procurement: game-theoretic studies of the tender process," 2015.

[27] M. Schmidt, "Price determination in public procurement: a game theory approach," European Financial and Accounting Journal, vol. 10, no. 1, pp. 49-62, 2015.

[28] M. Glad, Z. Lanović, and J. Pašagić, "Model for determining fixed costs for the winter service operation," Promet-Traffic \& Transportation, vol. 18, no. 4, pp. 285-291, 2006.

[29] J. Szep and F. Forgo, "Introduction to the theory of games," 1985.

[30] J. Duffy, "Game theory and nash equilibrium," Thunder Bay, vol. 18, 2015.

[31] M. Beckenkamp, "Playing strategically against nature? Decisions viewed from a game-theoretic frame," Max Plank Institute Collective Goods Preprint, vol. 9, 2008. 